Table 1S. Model chemistry energies (hartrees) of species used in the determination of binding energies of water clusters, $\left(\mathrm{H}_{2} \mathrm{O}\right)_{\mathrm{n}}, \mathrm{n}=1-6$.

CBS-QB3

\begin{tabular}{|c|c|c|c|c|}
\hline Species & $\mathrm{E}_{\mathrm{e}}$ & $\mathrm{E}_{0}$ & $\mathrm{H}_{298}$ & $\mathrm{G}_{298}$ \\
\hline Monomer & -76.358559 & -76.337457 & -76.333677 & -76.355104 \\
\hline Dimer & -152.725238 & -152.679703 & -152.672759 & -152.707433 \\
\hline Trimer & -229.099996 & -229.026871 & -229.018925 & -229.055669 \\
\hline Tetramer & -305.476651 & -305.378029 & -305.367735 & -305.410717 \\
\hline Pentamer & -381.848454 & -381.725189 & -381.711935 & -381.763622 \\
\hline Cyclic Hexamer & -458.219825 & -458.072253 & -458.055825 & -458.115201 \\
\hline Cage Hexamer & -458.224757 & -458.074125 & -458.059423 & -458.112570 \\
\hline Prism Hexamer & -458.226174 & -458.075063 & -458.060532 & -458.112699 \\
\hline
\end{tabular}

CBS-APNO

\begin{tabular}{|c|c|c|c|c|}
\hline Species & $\mathrm{E}_{\mathrm{e}}$ & $\mathrm{E}_{0}$ & $\mathrm{H}_{298}$ & $\mathrm{G}_{298}$ \\
\hline Monomer & -76.431962 & -76.410611 & -76.406831 & -76.428189 \\
\hline Dimer & -152.872001 & -152.826198 & -152.819136 & -152.853065 \\
\hline Trimer & -229.320924 & -229.248609 & -229.239558 & -229.278974 \\
\hline Tetramer & -305.772141 & -305.674152 & -305.662454 & -305.708876 \\
\hline Pentamer & -382.218405 & -382.095989 & -382.080884 & -382.137506 \\
\hline Cyclic Hexamer & -458.664400 & -458.517213 & -458.498911 & -458.562642 \\
\hline Cage Hexamer & -458.666322 & -458.517278 & -458.500157 & -458.559413 \\
\hline Prism Hexamer & -458.666956 & -458.517391 & -458.500549 & -458.558468 \\
\hline
\end{tabular}

G2

\begin{tabular}{|c|c|c|c|c|}
\hline Species & $\mathrm{E}_{\mathrm{e}}$ & $\mathrm{E}_{0}$ & $\mathrm{H}_{298}$ & $\mathrm{G}_{298}$ \\
\hline Monomer & -76.350522 & -76.330013 & -76.328277 & -76.349654 \\
\hline Dimer & -152.708987 & -152.664876 & -152.662027 & -152.696109 \\
\hline Trimer & -229.075758 & -229.005786 & -229.003450 & -229.042619 \\
\hline Tetramer & -305.445326 & -305.350675 & -305.348020 & -305.394332 \\
\hline Pentamer & -381.809486 & -381.691426 & -381.687693 & -381.744156 \\
\hline Cyclic Hexamer & -458.173138 & -458.031290 & -458.026580 & -458.090662 \\
\hline Cage Hexamer & -458.175894 & -458.031879 & -458.028481 & -458.087676 \\
\hline Prism Hexamer & -458.176357 & -458.031854 & -458.028719 & -458.086645 \\
\hline
\end{tabular}

G3

\begin{tabular}{|c|c|c|c|c|}
\hline Species & $\mathrm{E}_{\mathrm{e}}$ & $\mathrm{E}_{0}$ & $\mathrm{H}_{298}$ & $\mathrm{G}_{298}$ \\
\hline Monomer & -76.402555 & -76.382046 & -76.378266 & -76.399644 \\
\hline Dimer & -152.813302 & -152.769191 & -152.762109 & -152.796190 \\
\hline Trimer & -229.232782 & -229.162810 & -229.153909 & -229.192919 \\
\hline Tetramer & -305.655189 & -305.560538 & -305.548898 & -305.595208 \\
\hline Pentamer & -382.072155 & -381.954106 & -381.938994 & -381.995586 \\
\hline Cyclic Hexamer & -458.488569 & -458.346703 & -458.328345 & -458.392404 \\
\hline Cage Hexamer & -458.491314 & -458.347299 & -458.330209 & -458.389405 \\
\hline Prism Hexamer & -458.492115 & -458.347631 & -458.330783 & -458.388749 \\
\hline
\end{tabular}




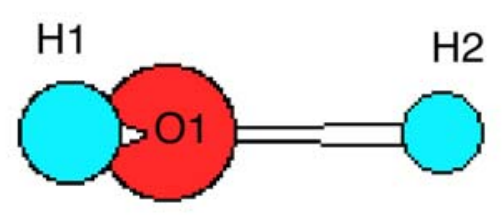

WATER DIMER

C2 symmetry

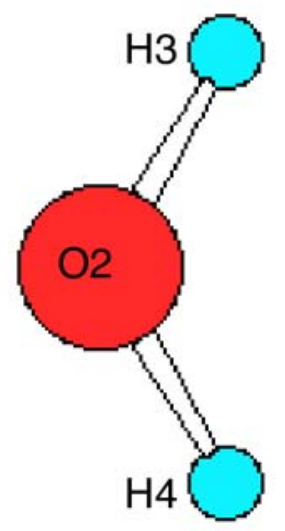

CBS-APNO CBS-QB3 G2/G3

$\begin{array}{llll}\mathrm{R}(\mathrm{O}-\mathrm{O}) & 2.925 & 2.886 & 2.914 \\ \mathrm{R}(\mathrm{H} 1-\mathrm{O} 1) & 0.957 & 0.961 & 0.968 \\ \mathrm{R}(\mathrm{H} 2-\mathrm{O} 1) & 0.962 & 0.970 & 0.975 \\ \mathrm{R}(\mathrm{H} 3 / 4-\mathrm{O} 2) & 0.959 & 0.963 & 0.971 \\ \mathrm{R}(\mathrm{H}---\mathrm{O}) & 1.966 & 1.926 & 1.955 \\ <(\mathrm{H}-\mathrm{O} 1-\mathrm{H}) & 102.7 & 103.9 & 104.2 \\ <(\mathrm{H}-\mathrm{O} 2-\mathrm{H}) & 103.5 & 104.7 & 104.2\end{array}$

Figure 1S Structure of the water dimer, with distances in $\AA$ and angles in degrees, for the QCISD/6-311G* geometry optimized with the CBS-APNO model chemistry, for the B3LYP/6-311G(2d,d,p) geometry optimized with the CBS-QB3 model chemistry, and for the MP2(Full)/6-31G* geometry optimized with the G2 \& G3 model chemistries. 
WATER TRIMER

C1 symmetry
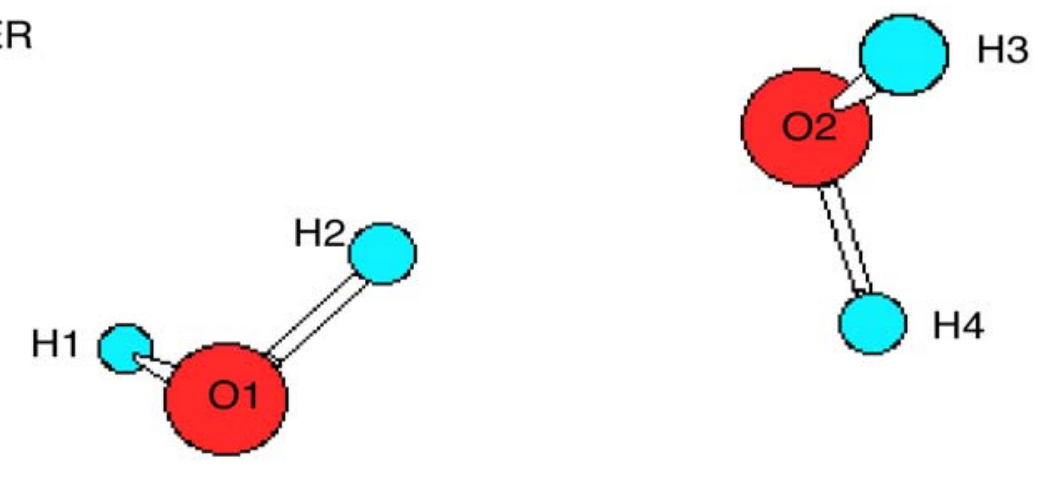

\begin{tabular}{|c|c|c|c|}
\hline \multicolumn{4}{|c|}{ CBS-APNO CBS-QB3 G2/G3 } \\
\hline O1-O2) & 2.810 & 2.764 & 2.785 \\
\hline -O3) & 2.802 & 2.761 & 2.796 \\
\hline (O3-O1) & 2.818 & 2.770 & 2.787 \\
\hline O-O1-O) & 60.3 & 60.2 & 60.2 \\
\hline$-02-0)$ & 60.0 & 60.0 & 59. \\
\hline O3-O) & 59.7 & 59.8 & 59.8 \\
\hline$-11 / 3 / 5)$ & 0.957 & 0.962 & 0.969 \\
\hline$(\mathrm{O}-\mathrm{H} 2 / 4 / 6)$ & 0.968 & 0.979 & 0.984 \\
\hline (O1---H6) & 1.917 & 1.859 & 1.874 \\
\hline (O2---H2) & 1.910 & 1.855 & 1.872 \\
\hline (O3---H4) & 1.934 & 1.873 & 1.892 \\
\hline $\mathrm{O} 1-\mathrm{H})$ & 105.0 & 103.7 & 104.6 \\
\hline$(\mathrm{H}-\mathrm{O} 2-\mathrm{H})$ & 105.3 & 105.3 & 104.9 \\
\hline$(\mathrm{H}-\mathrm{O} 3-\mathrm{H})$ & 104.8 & 103.6 & 104.4 \\
\hline (O1-H2---C & 2) 152.1 & 152.5 & 153.0 \\
\hline$-\mathrm{H} 4---\mathrm{C}$ & 3) 150.7 & 151.1 & 151.4 \\
\hline (O3-H6---C & 152.3 & 152.5 & 153.0 \\
\hline (H6---O1-H & 12) 88.8 & 87.5 & 87.1 \\
\hline$---\mathrm{O} 2-\mathrm{H}$ & 44) 87.6 & 88.3 & 88.0 \\
\hline H4---O3-H & 16) 87.8 & 87.5 & 87.1 \\
\hline
\end{tabular}

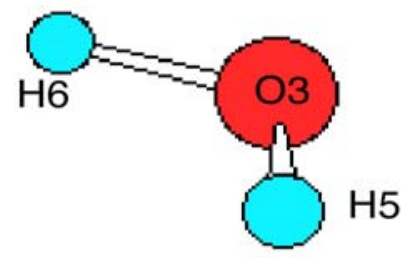

Figure 2S Structure of the water trimer, with distances in $\AA$ and angles in degrees, for the QCISD/6-311G* geometry optimized with the CBS-APNO model chemistry, for the B3LYP/6-311G(2d,d,p) geometry optimized with the CBS-QB3 model chemistry, and for the MP2(Full)/6-31G* geometry optimized with the G2 \& G3 model chemistries.

of 2.909 and $2.889 \AA$, with the later value found with full correlation of the $\mathrm{O}_{1 \mathrm{~s}}$ 
$\mathrm{Ha}$

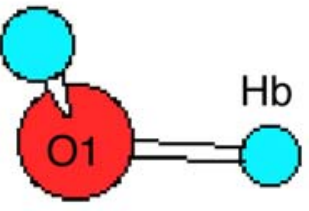

WATER TETRAMER

C2/S4 symmetry
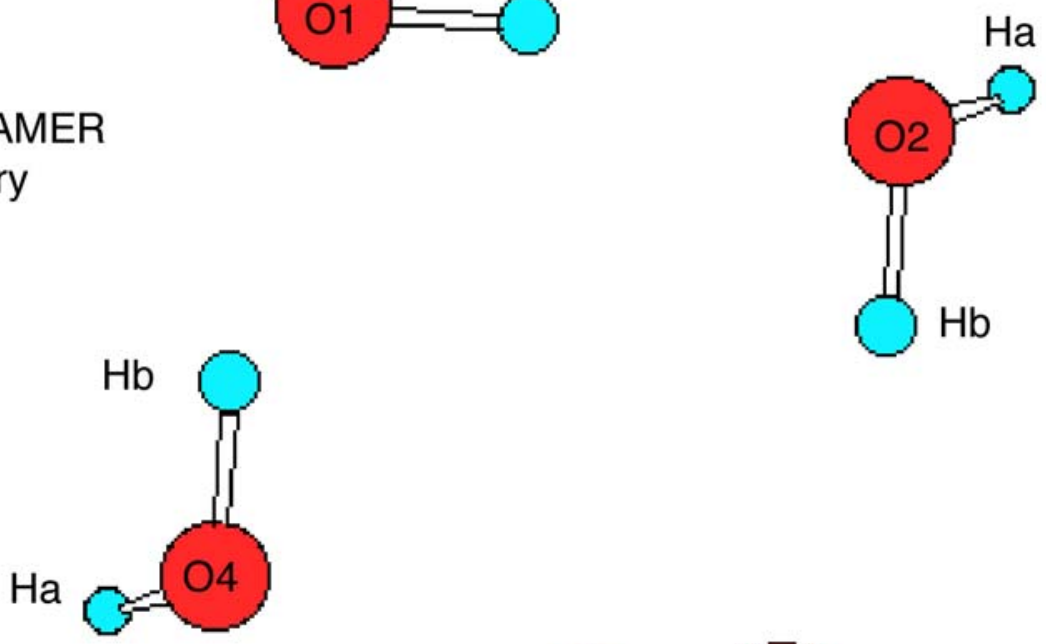

CBS-APNO CBS-QB3 G2/G3

$\begin{array}{lrrr}\mathrm{R}(\mathrm{O} 1-\mathrm{O} 2) & 2.754 & 2.714 & 2.748 \\ \mathrm{R}(\mathrm{O} 2-\mathrm{O} 3) & 2.763 & & \\ \mathrm{R}(\mathrm{O} 3-\mathrm{O} 4) & 2.749 & & \\ \mathrm{R}(\mathrm{O} 4-\mathrm{O} 1) & 2.752 & & \\ <(\mathrm{O}-\mathrm{O} 1-\mathrm{O}) & 89.5 & 89.4 & 90.0 \\ <(\mathrm{O}-\mathrm{O} 2-\mathrm{O}) & 89.8 & 90.0 & \\ <(\mathrm{O}-\mathrm{O}-\mathrm{O}) & 89.4 & 89.4 & \\ <(\mathrm{O}-\mathrm{O} 4-\mathrm{O}) & 90.0 & 90.0 & \\ \mathrm{R}(\mathrm{O}-\mathrm{Ha}) & 0.957 & 0.962 & 0.969 \\ \mathrm{R}(\mathrm{O}-\mathrm{Hb}) & 0.972 & 0.986 & 0.991 \\ \mathrm{R}(\mathrm{O}---\mathrm{Hb}) & 1.798 & 1.744 & 1.770 \\ <(\mathrm{H}--\mathrm{O} 1-\mathrm{H}) & 101.6 & 101.3 & 100.8 \\ <(\mathrm{H}--\mathrm{O} 2-\mathrm{H}) & 102.2 & 101.8 & \\ <(\mathrm{H}---\mathrm{O} 3-\mathrm{H}) & 101.8 & 101.4 & \\ <(\mathrm{H}---\mathrm{O} 4-\mathrm{H}) & 102.8 & 101.8 & \\ <(\mathrm{H}-\mathrm{O}-\mathrm{H}) & 103.8 & 105.1 & 104.5\end{array}$

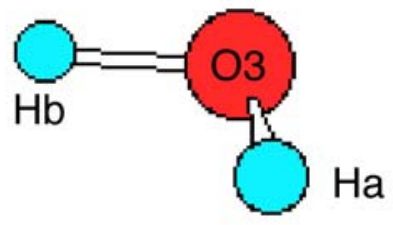

Figure 3S Structure of the water tetramer, with distances in $\AA$ and angles in degrees, for the QCISD/6-311G* geometry optimized with the CBS-APNO model chemistry, for the B3LYP/6-311G(2d,d,p) geometry optimized with the CBS-QB3 model chemistry, and for the MP2(Full)/6-31G* geometry optimized with the G2 \& G3 model chemistries. 


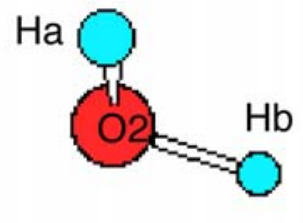

\section{WATER PENTAMER}

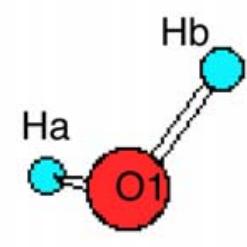

$\mathrm{Hb}$

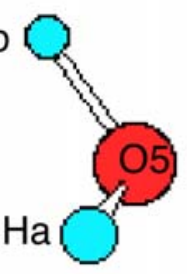

CBS-APNO CBS-QB3 G2/G3

$\begin{array}{cccc}\mathrm{R}(\mathrm{O}-\mathrm{O}) 1-2 & 2.729 & 2.690 & 2.737 \\ 2-3 & 2.729 & 2.690 & 2.737 \\ 3-4 & 2.732 & 2.694 & 2.738 \\ 4-5 & 2.747 & 2.705 & 2.750 \\ 5-1 & 2.734 & 2.695 & 2.739 \\ (\mathrm{O}-\mathrm{O}-\mathrm{O})<5-1-2 & 107.4 & 107.8 & 108.0 \\ <1-2-3 & 108.4 & 108.1 & 107.7 \\ <2-3-4 & 107.1 & 107.2 & 108.6 \\ <3-4-5 & 108.0 & 108.1 & 107.3 \\ <4-5-1 & 107.2 & 107.1 & 108.2 \\ \mathrm{R}(\mathrm{O}-\mathrm{Hb}) & 0.974 & 0.988 & 0.991 \\ \mathrm{R}(\mathrm{O}-\mathrm{Ha}) & 0.957 & 0.961 & 0.969\end{array}$

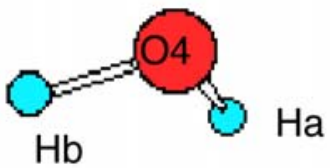

Figure 4S Structure of the water pentamer, with distances in $\AA$ and angles in degrees, for the QCISD/6-311G* geometry optimized with the CBS-APNO model chemistry, for the B3LYP/6-311G(2d,d,p) geometry optimized with the CBS-QB3 model chemistry, and for the MP2(Full)/6-31G* geometry optimized with the G2 \& G3 model chemistries. 


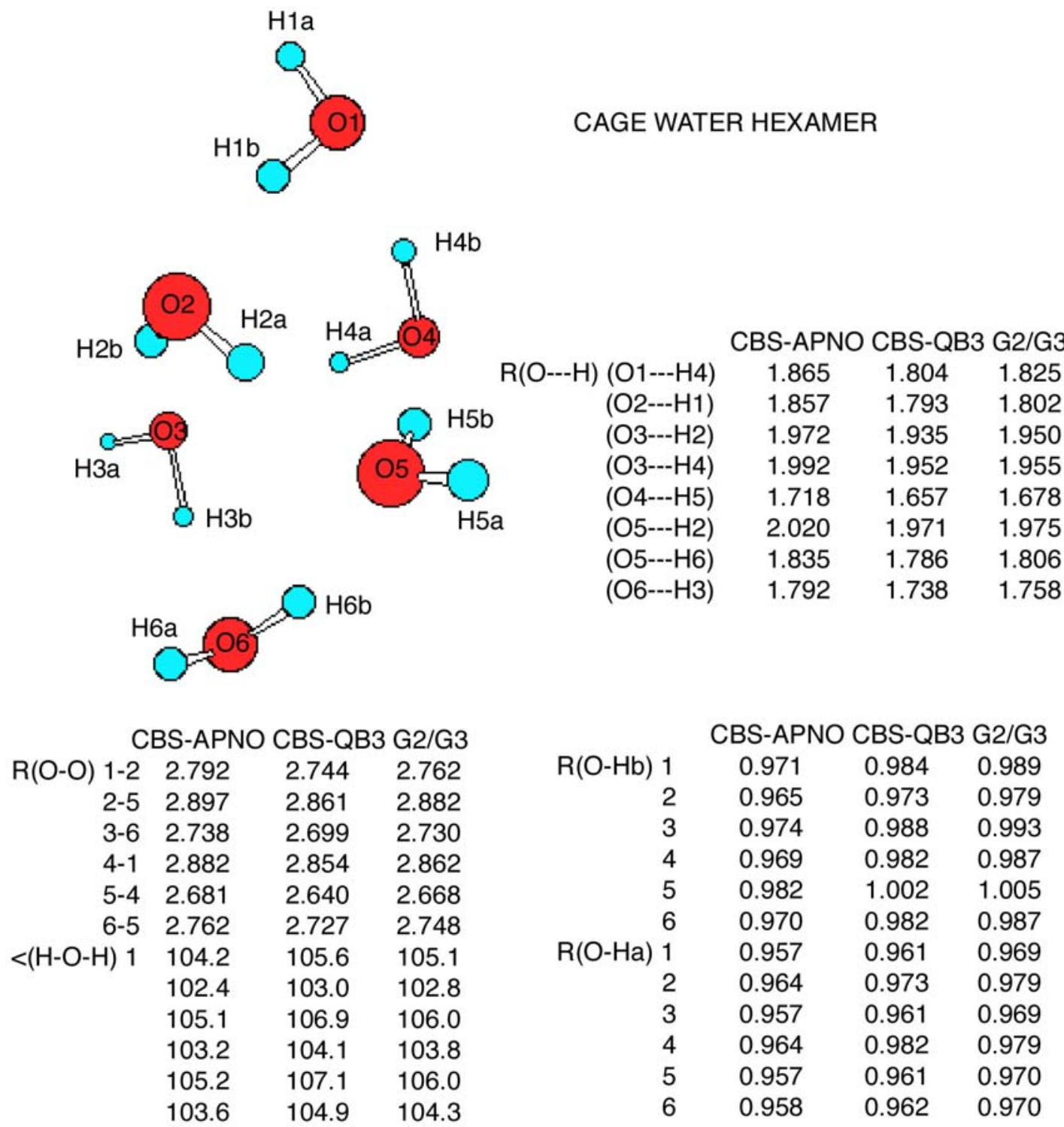

Figure 5S Structure of the water Cage hexamer, with distances in $\AA$ and angles in degrees, for the QCISD/6-311G* geometry optimized with the CBS-APNO model chemistry, for the B3LYP/6-311G(2d,d,p) geometry optimized with the CBS-QB3 model chemistry, and for the MP2(Full)/6-31G* geometry optimized with the G2 \& G3 model chemistries. 
CYCLIC WATER HEXAMER

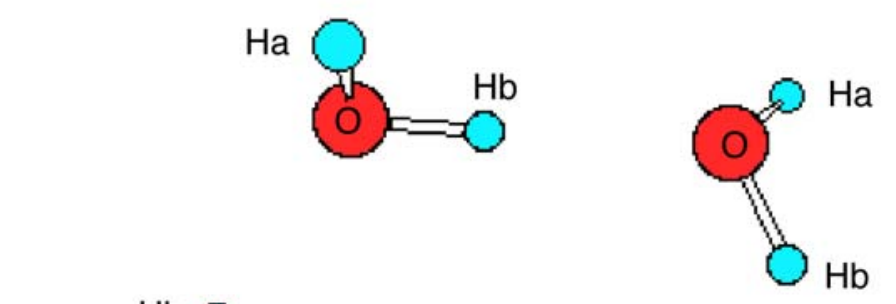

S6 symmetry

$\mathrm{Ha}$

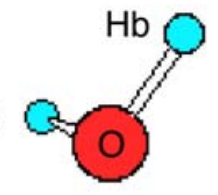

\begin{tabular}{lcccc}
\multicolumn{5}{c}{ CBS-APNO CBS-QB3 G2/G3 } \\
$\mathrm{R}(\mathrm{O}-\mathrm{O})$ & 2.723 & 2.684 & 2.735 & \\
$<(\mathrm{O}-\mathrm{O}-\mathrm{O})$ & 119.4 & 119.5 & 120.0 & $\mathrm{Hb}$ \\
$\mathrm{R}(\mathrm{O}-\mathrm{Hb})$ & 0.974 & 0.987 & 0.991 & \\
$\mathrm{R}(\mathrm{O}-\mathrm{Ha})$ & 0.957 & 0.961 & 0.969 & \\
$\mathrm{R}(\mathrm{O}--\mathrm{H})$ & 1.752 & 1.700 & 1.747 & \\
$<(\mathrm{H}-\mathrm{O}-\mathrm{H})$ & 103.5 & 104.8 & 104.1 & \\
$<(\mathrm{H}---\mathrm{O}-\mathrm{H})$ & 174.9 & 174.4 & 174.9 & $\mathrm{Ha}$
\end{tabular}

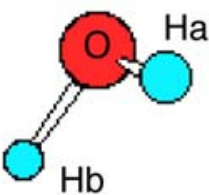

Figure 6S Structure of the water Cyclic hexamer, with distances in $\AA$ and angles in degrees, for the QCISD/6-311G* geometry optimized with the CBS-APNO model chemistry, for the B3LYP/6-311G(2d,d,p) geometry optimized with the CBS-QB3 model chemistry, and for the MP2(Full)/6-31G* geometry optimized with the G2 \& G3 model chemistries. 


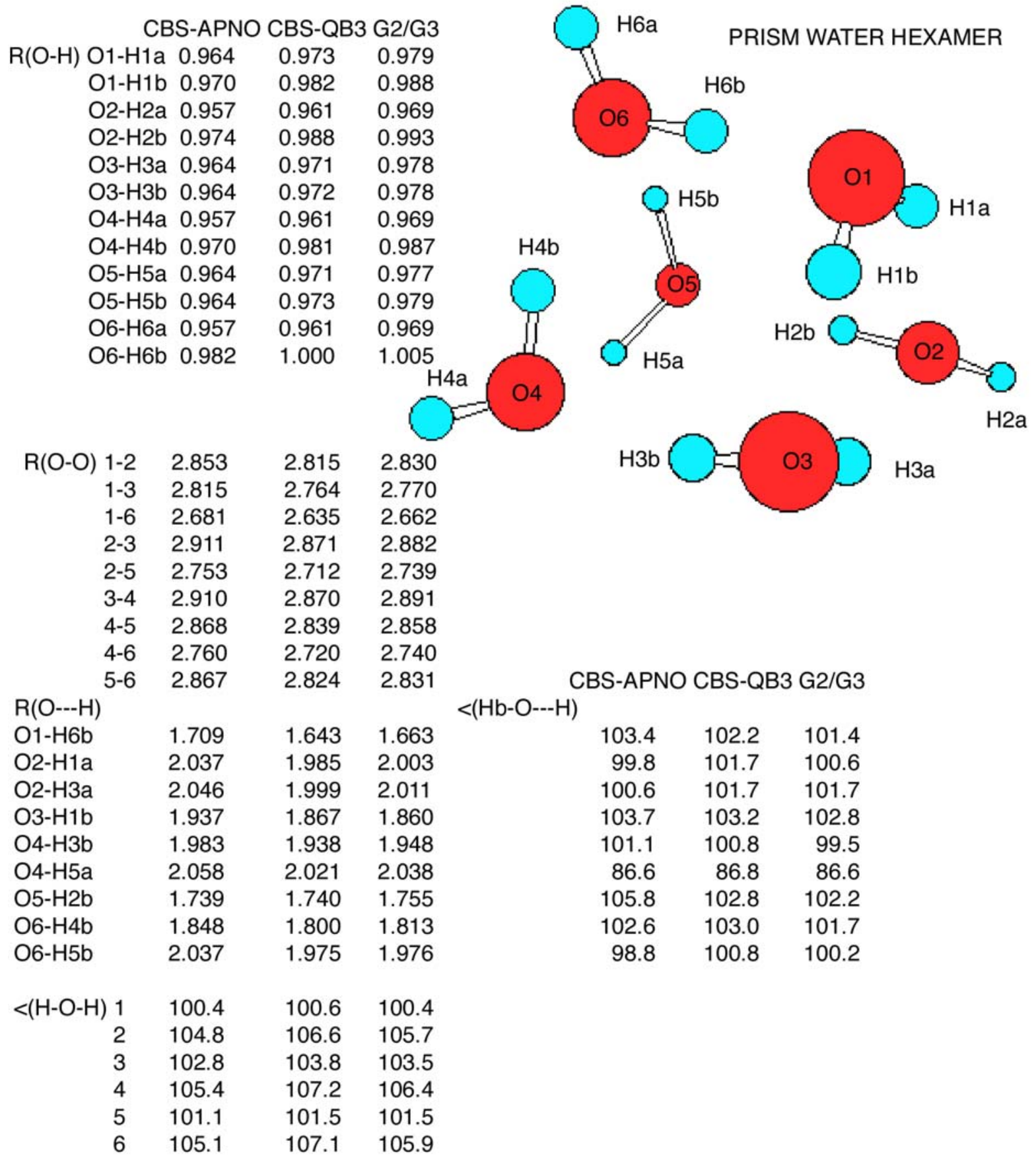

Figure 7S Structure of the water Prism hexamer, with distances in $\AA$ and angles in degrees, for the QCISD/6-311G* geometry optimized with the CBS-APNO model chemistry, for the B3LYP/6-311G(2d,d,p) geometry optimized with the CBS-QB3 model chemistry, and for the MP2(Full)/6-31G* geometry optimized with the G2 \& G3 model chemistries. 